Araştırma Makalesi - Research Article

\title{
Art Arda Yerleştirilmiş Eş Sıcaklıktaki İki Silindir Etrafında Akış ve Isı Geçişi
}

\author{
Zerrin SERT $^{1 *}$, Çisil TIMMURALP ${ }^{2}$
}

Revize / Revised: 31/05/2020

Kabul / Accepted: 08/06/2020

\section{$\ddot{\text { öz }}$}

Bu çalışmada, ard ard yerleştirilen eş sıcaklıktaki iki silindir etrafındaki akış ve ısı geçişi geçici rejimde sayısal olarak incelenmiştir. İki boyutlu, geçici rejimde süreklilik, momentum ve enerji denklemleri Fluent yazılımı kullanılarak çözdürülmüştür. Çalışma akışkanı olarak hava $(\operatorname{Pr}=0.7)$ ve su $(\operatorname{Pr}=7)$ seçilmiştir. Reynolds sayısı 100, 150 ve 200 olarak alınmıştır. Ayrıca silindir merkezleri arasındaki uzaklık, L/D=1.5 ve 5 olarak seçilmiştir. Her durum için elde edilen sürükleme katsayısı, kaldırma katsayısı ve Nusselt sayısı gibi akış ve 1sı transfer parametreleri, literatürdeki mevcut çalışmalarla karşılaştırılmıştır. L/D=1.5 olduğunda iki silindir arasında girdaplar oluşmazken, L/D=5 durumunda iki silindir arasında girdapların oluştuğu görülmektedir. Ayrıca Reynolds sayısının artması ile aşağı akış bölgesinde vorteksler ikinci silindire daha yakın bir mesafede oluşmuştur.

Anahtar Kelimeler- Art arda silindirler, Geçici rejim, Isı geçişi, Zorlanmış taşınım

1*Sorumlu yazar iletişim: zbocu@ogu.edu.tr (https://orcid.org/0000-0001-6934-5443)

Makine Mühendisliği, Eskişehir Osmangazi Üniversitesi, Mühendislik-Mimarlık Fakültesi, Eskişehir, Türkiye

2İletişim: cisil@ogu.edu.tr (https://orcid.org/0000-0002-2894-3575)

Makine Mühendisliği, Eskişehir Osmangazi Üniversitesi, Mühendislik-Mimarlık Fakültesi, Eskişehir, Türkiye 


\title{
Numerical Investigation of Heat Transfer and Fluid Flow Around Two Tandem Cylinders
}

\begin{abstract}
In this study, the unsteady flow and heat transfer from two tandem cylinders are studied numerically. For twodimensional transient state continuity, Navier-Stokes and energy equations are solved using Fluent ${ }^{\circledR}$ software. The working fluids are considered as air $(\mathrm{Pr}=0.7)$ and water $(\mathrm{Pr}=7)$. The simulations are performed for Reynolds numbers of 100,150 and 200 . The distance between the cylinders is also taken as $\mathrm{L} / \mathrm{D}=1.5$ and $\mathrm{L} / \mathrm{D}=5$. The flow and heat transfer characteristics such as drag coefficient, lift coefficient and Nusselt number obtained for each case are compared with the studies in the literature. For $\mathrm{L} / \mathrm{D}=5$, the vortex shedding observed between the cylinders while no vortex is observed for $\mathrm{L} / \mathrm{D}=1.5$. With an increase in the Reynolds number, vortices are formed closer to the second cylinder in the downstream region.
\end{abstract}




\section{GİRIȘ}

Akışkana dalmış cisimler üzerinde akışa, 1sı değiştiricileri, bacalar, buhar jeneratörleri gibi birçok mühendislik uygulamasında rastlamak mümkündür. Bir cisme etkiyen dış akış, cismin arkasında girdaplar oluşturarak karmaşık ve zamana göre değişen bir davranış sergilemektedir. Dalmış cisimler etrafındaki akışın düzensiz yapısı yıllardır birçok araştırmacı tarafından incelenmiştir. Silindirlerin art arda yerleştirilmesi akışın ve 1Sı geçişinn daha karmaşık olmasına yol açmaktadır.

Farrant vd. [1], art arda ve çapraz dizilmiş durumlar için dairesel silindirler etrafında iki boyutlu geçici sıkıştırılamaz akışları Reynolds sayısı 200 için incelemişlerdir. Çözümler eşit çaplı, eşit aralıklı dört silindir ve biri dairesel diğeri eliptik iki silindir için verilmiş̧ir. Meneghini vd. [2] aynı Reynolds sayılarında alt alta ve art arda dizilmiş iki dairesel silindir arasındaki akışı ve vortex oluşumunu 2 boyutlu nümerik olarak çalışmışlardır. Buyruk [3] ise $\mathrm{Re}=400$ değerinde art arda dizilmiş iki izotermal silindirden, $\mathrm{Re}=80,120$ ve 200 değerlerinde ise şaşırtmalı dizilmiş üç ve dörtgensel dizilmiş dört silindirden 1sı transferini nümerik olarak çözmüştür. Kondo ve Matsukuma [4], Re $=1000$ için art arda dizilmiş iki dairesel silindir etrafındaki akışları 2 ve 3 boyutlu sayısal olarak incelemişlerdir. İki silindir merkezi arasındaki mesafe 2D ve 5D alınmış, sayısal sonuçlar deneysel verilerle karşılaştırılmıştır. Carmo ve Meneghini [5], art arda dizilmiş bir çift dairesel silindir etrafındaki sıkıştırılamaz akışın 2 ve 3 boyutlu simülasyonlarını, spektral eleman yöntemi kullanarak araştırmışlardır. İncelenen konfigürasyonlarda merkezler arası mesafe 1.5D ile 8D arasında değişirken Reynolds sayısı için 160 ila 320 aralığında değişen değerler alınmıştır. Eşit olmayan boyutlardaki silindir dizileri etrafındaki su akışını 2 boyutlu, laminer ve geçici durumda $\mathrm{Re}=150$ için Huang vd. [6] Fluent programı kullanarak çözmüşlerdir. Bir silindir sırası için, silindir eksenleri arasındaki boşluk 4D olduğunda girdap caddesinin stabil olduğu, boşluk 2.5D olduğunda ise silindirler arkasındaki girdapların birleşip senkronize şekilde hareket ettiği gözlenmiştir. Re sayısı için 100 ve 200 değerlerinin alındığı art arda ve alt alta dizili iki dairesel silindir etrafındaki akışı Ding vd. [7] çalışmışlardır. Mahir ve Altaç [8] Re= 100 ve 200, iki silindir arası mesafe 2D, 3D, 4D, 5D, 7D ve 10D ve $\mathrm{Pr}=0.7$ için iki silindir arkasında oluşan girdapları ticari Fluent programı ile analiz etmişlerdir. Çalışmaları sonucunda literatüre yeni bir Nusselt korelasyonu kazandırmışladır. Chatterjee ve Mondal [9] çalışmalarında, arka arkaya dizilmiş eş 2 kare silindir arasında girdapların oluştuğu farklı Re sayıları için kritik boşluk oranı olduğunu göstermişlerdir. Abbasi vd. [10] dörtgensel yerleştirilmiş 4 kare silindirde, aralığın bir kenar uzunluğuna oranını 1, 3 ve 6 alarak Reynolds sayısını da 60 ile 175 aralığında değiştirerek akışı incelemişlerdir. Islam vd. [11] sabit $\mathrm{Re}=150$ değerinde alt alta sıralanmış 5 silindirden geçen akışa silindirler arasındaki mesafenin etkisini incelemişler ve farklı akış modellerinin oluştuğunu gözlemlemişlerdir. Zhang vd. [12] sabit $\mathrm{Re}=100$ için art arda yerleştirilmiş iki izotermal dikdörtgen silindir boyunca zorlanmış taşınıma en/boy oranının ve dikdörtgenler arası mesafe oranının etkisini incelemişlerdir. Tüm en/boy oranları için, silindirler arasındaki boşluk oranının 3 veya daha küçük değerlerinde sürekli, 4 veya 4 'ten büyük değerlerinde ise geçici rejim gözlenmiştir. Shaaban ve Mohany [13] Re=200 için eşit aralıklarla üç sıralı yerleştirilmiş silindirlerden geçen akışı araştırmışlardır. İlk iki silindir arasındaki mesafe $1.05 \mathrm{D}-2.95 \mathrm{D}$ aralığında değiştirilirken silindirler arasındaki mesafeye bağlı olarak $1.6 \mathrm{D}$ ve $1.8 \mathrm{D}$ 'de iki farklı girdap kopması olduğunu görmüşlerdir. Zhang vd. [14] dörtgensel şekilde dizilmiş 4 kare silindirdeki akışı altkritik Re sayısı 800 için deneysel olarak çalışmışlardır. Silindir merkezleri arasındaki mesafenin çapa oranı $2-5$ aralığında değiştirilirken silindirler $0^{\circ}-45^{\circ}$ aralığında 7 farklı açı verilerek konumlandırılmıştır. Bu çalışmalarda yalın zorlanmış taşınım etkin olup, doğal taşınım ile olan ısı geçişi ihmal edilmiştir.

Silindirlerin akışkandan daha sıcak olduğu durumlarla ilgili çalışmalar da literatürde bulanabilir. Bu durumdaki çalışmalarda hem zorlanmış hem de doğal taşınım etkileri çalışılmıştır. İki plaka arasına dik açılı ikizkenar üçgen şeklinde yerleştirilmiş silindirlerdeki zorlanmış taşınımı Re sayısının 100-300 aralığındaki değerleri ve Grashof sayısının 80000 ve 200000 değerleri için sürükleme katsayısı ve zaman ortalama Nu sayısı değişimini Jue vd. [15] araştırmışlardır. Rahnama ve Hadi-Moghaddam [16] yaptıkları 2 boyutlu nümerik çalışmada içerisinde 1sıtılmış kare silindir bulunan kanal içindeki ssı transferini Richardson (Ri) sayısını 0.0032 alarak geçici laminer akış için çözmüşler ve elde ettikleri zaman ortama $\mathrm{Nu}$ sayısı, sürükleme katsayısı ve Strouhal sayısını literatür ile karşılaştırmışlardır. Chatterjee ve Mondal [17] yaptıkları nümerik, 2 boyutlu çalışmalarında art arda dizilmiş izotermal iki kare silindir etrafında çapraz akışlı Newtonian akışkan için bileşik 1S1 taşınımını sunmuşlardır. Re sayısı 50-150 aralığında değişirken Richardson sayısı 0-2 aralığında değiştirilmiştir. Barros vd. [18], üçgen düzende yerleştirilmiş üç silindir etrafındaki akışı araştırmış ve $R e=100$, $\operatorname{Pr}=0.71$ ve Ri sayısının 0.1-10 aralığındaki değerlerinde çeşitli optimum mesafe oranları için Ri sayısının, 
sürükleme katsayısı ve Nu sayısı üzerindeki etkilerini sunmuşlardır. Sunakranei vd. [19] art arda dizilmiş eliptik silindirlerdeki akış ve 1sı transferini $\mathrm{Re}=50-200$ aralığında farklı mesafe ve eksen oranları için nümerik olarak çalışmışlar ve mesafe oranı, eksen oranı ve Reynolds sayısının bir fonksiyonu olarak sürükleme ve Nusselt sayısı için korelasyonlar türetmişlerdir.

Bu çalışmada Reynolds sayısı 100, 150 ve 200 için iki silindir arası mesafe değişiminin akış ve 1sı geçişine etkisi sayısal olarak incelenmiştir. Silindir merkezleri arası uzaklık L/D=1.5 ve 5 olarak alınmıştır. Literatür çalışmaları incelendiğinde çalışmalarda bir çeşit akışkan (hava) kullanıldığı görülmektedir. Fakat bu çalışmada Prandtl sayısı farklı olan hava $(\operatorname{Pr}=0.7)$ ve su $(\operatorname{Pr}=7)$ akışkan olarak seçilmiştir. Bu şekilde akışkan özelliğinin; farklı Reynolds sayısı ve farklı silindir merkezleri uzaklığında iz bölgesindeki akış değişimi ve ısı geçişi ayrıntılı olarak incelenmiştir.

\section{PROBLEMIN TANIMI}

28.5D+L uzunluğunda, 20D genişliğinde bir kanala art arda yerleştirilen iki silindirin akış ve 1S1 transferi analizi yapılmıştır. Silindir çapları D olarak alınmıştır. Problemin şematik gösterimi ve koordinat sistemi Şekil 1'de görülmektedir. Kanaldaki iki silindir $U_{\infty}$ hızında ve $T_{\infty}$ sıcaklığında akışkana maruz kaldığ kabul edilmiştir. Çalışmadaki akışkan hava $(\operatorname{Pr}=0.7)$ ve su $(\operatorname{Pr}=7)$ 'dur. Art arda yerleştirilen iki silindir arası mesafe $\mathrm{L}=1.5 \mathrm{D}$ ve $5 \mathrm{D}$ olarak seçilmiştir. Ayrıca Reynolds sayısının akış parametreleri ve ısı geçişi üzerindeki etkisini incelemek için Reynolds sayısı 100, 150 ve 200 olarak alınmıştır.

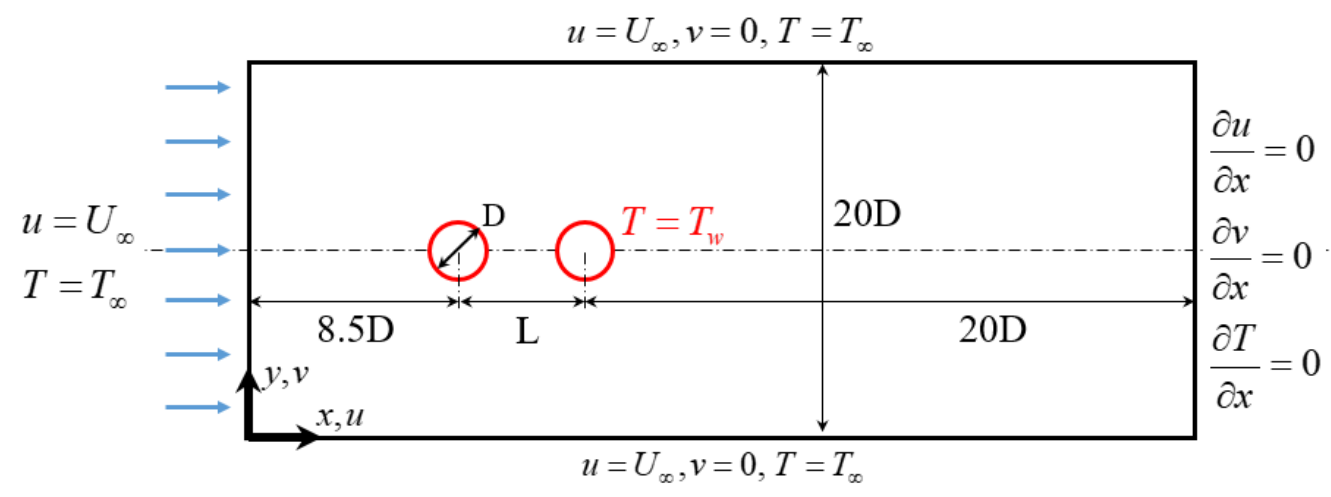

Şekil 1. Çalışmada ele alınan geometrinin detayları ve sınır şartları

Tanımlanan bu problemin geçici rejimde, sıkıştırılamaz akış için karakterize eden genel denklemler aşağıdaki gibi ifade edilebilir [8].

Süreklilik Denklemi:

$\frac{\partial u}{\partial x}+\frac{\partial v}{\partial y}=0$

x-momentum Denklemi:

$$
\frac{\partial u}{\partial t}+u \frac{\partial u}{\partial x}+v \frac{\partial u}{\partial y}=-\frac{1}{\rho} \frac{\partial p}{\partial x}+v\left(\frac{\partial^{2} u}{\partial x^{2}}+\frac{\partial^{2} u}{\partial y^{2}}\right)
$$


y-momentum Denklemi:

$$
\frac{\partial v}{\partial t}+u \frac{\partial v}{\partial x}+v \frac{\partial v}{\partial y}=-\frac{1}{\rho} \frac{\partial p}{\partial y}+v\left(\frac{\partial^{2} v}{\partial x^{2}}+\frac{\partial^{2} v}{\partial y^{2}}\right)
$$

Enerji Denklemi:

$$
\frac{\partial T}{\partial t}+u \frac{\partial T}{\partial x}+v \frac{\partial T}{\partial y}=\alpha\left(\frac{\partial^{2} T}{\partial x^{2}}+\frac{\partial^{2} T}{\partial y^{2}}\right)
$$

Burada $(u, v)$ sırasıyla, $(x, y)$ koordinat sistemine karşılık gelen hız bileşenlerini, $p$ basıncı, $v$ kinematik viskoziteyi, $\rho$ akışkanın yoğunluğu, $T$ sıcaklığı $\alpha\left(=k / \rho c_{p}\right)$ 1sı yayınım katsayısını, $k$ akışkanın ısı iletim katsayısını, $c_{p}$ akışkanın özgül ısı kapasitesini temsil etmektedir. verilmiştir [8].

Yönetici denklemlerin çözümünde kullanılacak olan ve problemi tanımlayan sınır şartlar aşağıda

Giriş: $u=U_{\infty}, T=T_{\infty}$

Alt ve üst cidarlar: $u=U_{\infty}, v=0, T=T_{\infty}$

Silindir cidarları: $u=0, v=0, T=T_{w}$

$$
\text { Çıkış: } \frac{\partial u}{\partial x}=0, \frac{\partial v}{\partial x}=0, \frac{\partial T}{\partial x}=0
$$

Sınır şartlardaki $T_{w}$ silindir duvar sıcaklığını $T_{\infty}$ ve $U_{\infty}$ ise sırasıyla gelen akışkanın sıcaklığını ve hızını göstermektedir.

Reynolds sayısı $\operatorname{Re}=U_{\infty} D / v$ olarak tanımlanmıştır. Silindirler üzerinden hesaplanan kaldırma ve sürüklenme katsayıları Denklem (5)'teki eşitliklerden yararlanılarak hesaplanmıştır. Akışa göre öndeki silindir için alt indis 1, arkadaki silindir için ise alt indis 2 imgesi kullanılmıştır.

$$
C_{\mathrm{L}}=\frac{F_{L}}{\frac{1}{2} \rho U_{\infty}^{2} A}, \quad C_{\mathrm{D}}=\frac{F_{D}}{\frac{1}{2} \rho U_{\infty}^{2} A}
$$

Bu denklemlerdeki $F_{L}$ ve $F_{D}$ sirasıyla kaldırma ve sürüklenme kuvvetini, A iz düşüm alanını ifade etmektedir. Ayrıca özellikle belli bir salınım frekansına sahip olan akım problemlerinde oldukça önemli olan ve $S t=f D / U_{\infty}$ ile ifade edilen boyutsuz Strouhal sayısıda hesaplanmıştır. Burada $f$ frekansı temsil etmektedir.

Sıcak silindir üzerinden alan ortalamalı hesaplanmış ortalama Nusselt sayısı,

$$
N u=\int_{A_{s}} N u_{s} d A_{s} / A_{s}
$$

ile hesaplanmaktadır. Ortalama Nusselt sayısı da arka ve öndeki silindir için ayrı ayrı hesaplanmıştır. 


\section{NÜMERİK ÇÖZÜM ve DOĞRULAMA}

Belirtilen sınır şartlara göre genel korunum denklemleri ticari yazılım olan Fluent® programı ile çözdürülmüştür. İki boyutlu geçici rejimde, süreklilik, Navier-Stokes ve enerji denkleminde çözüm algoritması olarak SIMPLE algoritması ile taşınım terimlerinin ayrıklaştırılmasında ikinci dereceden ileri farklar (Second Order Upwind) ayrıklaştırma yöntemi kullanılmıştır. Tüm denklemlerin yakınsama kriteri $10^{-6}$ olarak seçilmiştir. Ayrıca çözümlemelerde zaman aralığı (time step) doğruluğu Mahir ve Altaç [8]'ın çalışmasında da tespit edilmiş olan 0.05 olarak seçilmiştir. Akış süresi (flow time) her bir durumda 850 değerini geçinceye kadar devam ettirilmiştir.

Yapılan çalışmada ağdan bağımsız çözümler elde edebilmek için $\operatorname{Pr}=0.7$ ve L/D=2 için iki farklı ağ yapısı literatürdeki çalışmalarla karşılaştırılmıştır. Re=100 ve 200 değerleri için yapılan sayısal çözümler literatür ile kıyaslanmış ve bu kıyaslama değerleri Tablo 1'de verilmiştir. Ağ yapısı 1'de 23110 düğüm noktası, 45659 hücre varken; Ăg yapısı 2'de 86671 düğüm noktası, 172157 hücre hücre mevcuttur. Literatür değerleri ile kıyaslama yapıldığında ağ yapısı 1'in yeterli olduğu sonucuna varılmıştır. Özellikle her iki silindir için hesaplanan ortalama Nusselt sayılarında $\left(\mathrm{Nu}_{1} \mathrm{ve} \mathrm{Nu}_{2}\right)$ hem ağ yapısı 1'in hemde ă̆ yapısı 2'nin literatürdeki değerleri ile karşılaştırıldığında fark \%1'den daha azdır. Bu yüzden optimum ağ yapısı olarak ağ yapısı 1 seçilmiştir.

Tablo 1. $\mathrm{L} / \mathrm{D}=2$ ve $\operatorname{Pr}=0.7$ için bu çalışmadaki sayısal çözümlerin literatür ile kıyaslanması

\begin{tabular}{|c|c|c|c|c|c|c|c|c|}
\hline$R e$ & & $N u_{I}$ & $N u_{2}$ & $C_{\mathrm{D}, 1}$ & $C_{L, 1}$ & St & $C_{\mathrm{D}, 2}$ & $C_{L, 2}$ \\
\hline \multirow{3}{*}{8} & Ăg Yapısı 1 & 4.771 & 2.034 & 1.214 & \pm 0.008 & 0.127 & \pm 0.00013 & \pm 0.0307 \\
\hline & Ağ Yap1sı 2 & 4.738 & 2.021 & 1.211 & \pm 0.0037 & 0.117 & \pm 0.000093 & \pm 0.0135 \\
\hline & Mahir ve Altaç [8] & 4.740 & 2.030 & 1.225 & \pm 0.0075 & - & \pm 0.00012 & \pm 0.0258 \\
\hline \multirow{5}{*}{ § } & A $\breve{g}$ Yap1s1 1 & 6.458 & $2.88 \pm 0.03$ & $1.089 \pm 0.0005$ & \pm 0.0425 & 0.137 & $-0.194 \pm 0.0054$ & \pm 0.182 \\
\hline & Ağ Yapısı 2 & 6.451 & $2.87 \pm 0.03$ & $1.082 \pm 0.0005$ & \pm 0.0405 & 0.137 & $-0.199 \pm 0.0051$ & \pm 0.177 \\
\hline & Mahir ve Altaç [8] & 6.460 & $2.88 \pm 0.03$ & $1.06 \pm 0.0004$ & \pm 0.034 & - & $-0.21 \pm 0.0036$ & \pm 0.17 \\
\hline & Meneghini vd. [2] & - & - & 1.030 & - & 0.130 & -0.170 & - \\
\hline & $\begin{array}{l}\text { Slaouti ve Stansby } \\
{[20]}\end{array}$ & - & - & $0.89 \pm 0.05$ & \pm 0.2 & 0.130 & $-0.21 \pm 0.15$ & - \\
\hline
\end{tabular}

Çözümlerde kullanılan ağ yapısı Şekil 2'de verilmiştir. Bu tip problemlerde ayrılan sınır tabaka etkileşimlerinin daha karmaşık olmasından dolayı düğüm sayısı ve bunların dağılımı çok önemlidir. A $\breve{g}$ yapısında üçgen elemanlar kullanılmış olup, silindir etrafında ve aşağı akış bölgesinde daha yoğun olacak şekilde üniform olmayan ağ yapısı oluşturulmuştur.

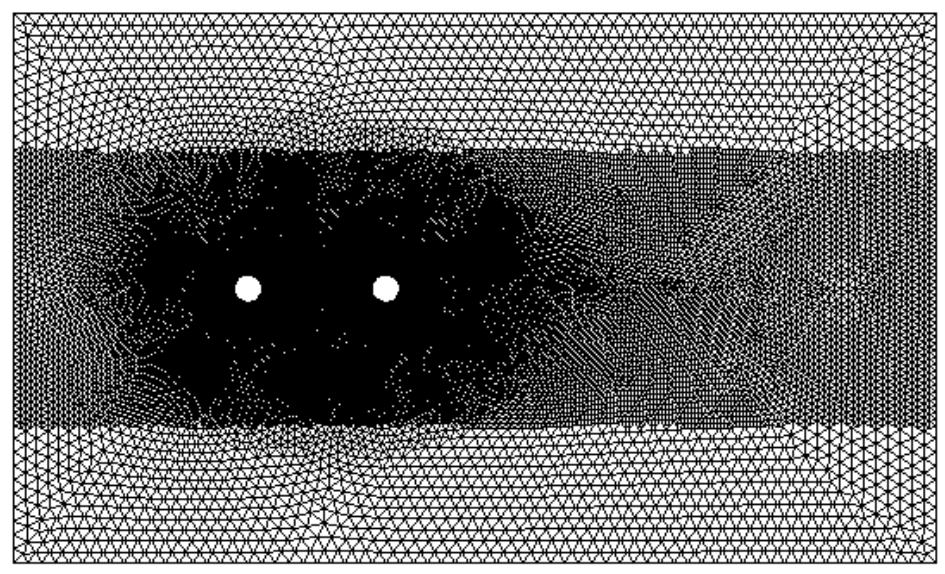

Şekil 2. Çözümlerde kullanılan ağ yapısı 


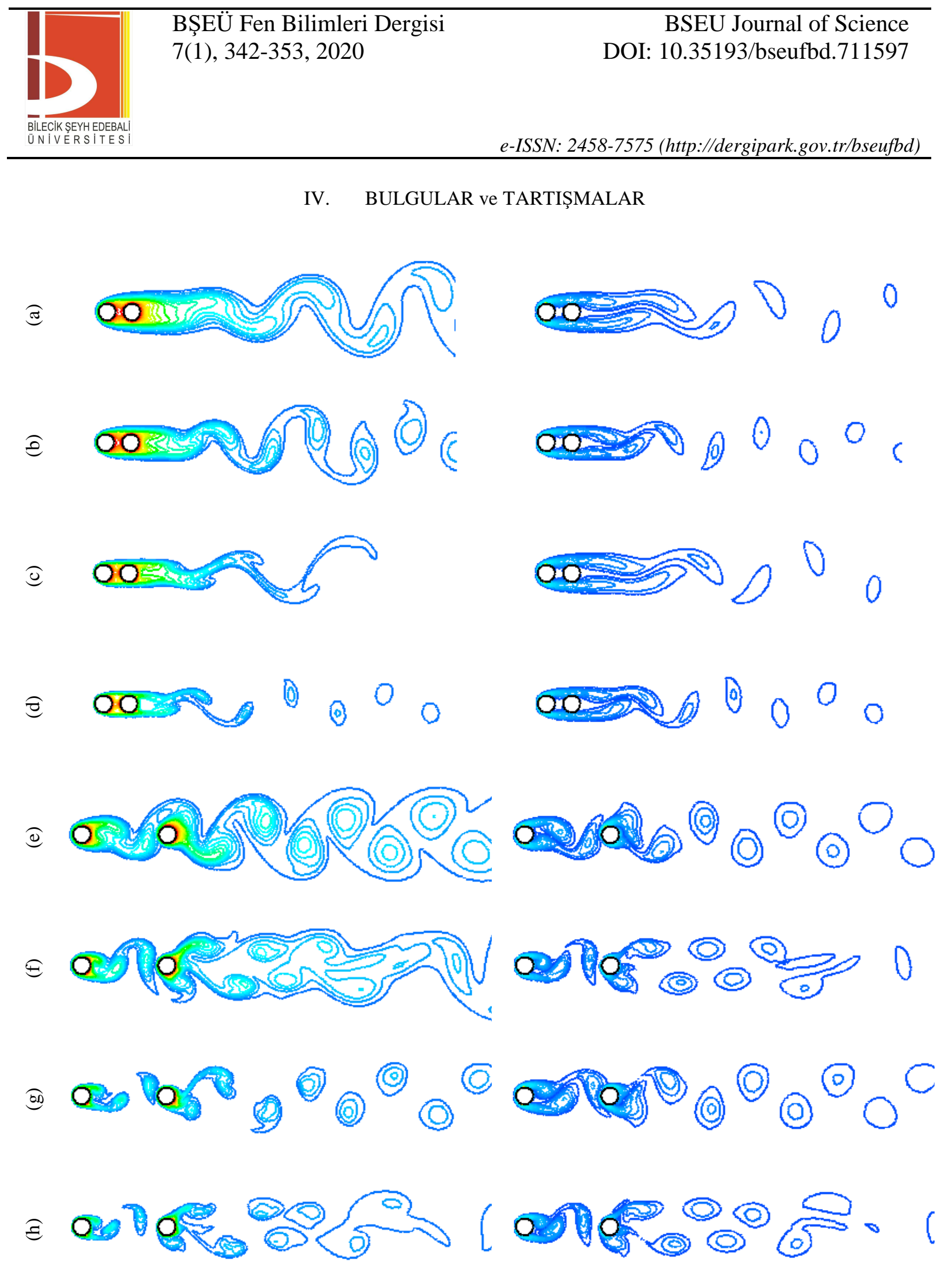

Şekil 3. $\mathrm{L} / \mathrm{D}=1.5$ (a, b, c, d) ve $\mathrm{L} / \mathrm{D}=5$ (e, f, g, h), $\mathrm{Re}=100$ (a, b, e, f) ve $\mathrm{Re}=200$ (c, d, g, h), Pr=0.7 (a, c, e, g) ve Pr=7 (b, d, f, h) için eş sicaklık eğrileri (solda) ve girdap eğrileri (sağda) 
Şekil 3'de eş sıcaklık eğrileri (solda) ve girdap eğrileri (sağda), $\mathrm{L} / \mathrm{D}=1.5$ ve 5 ve farklı Reynolds ve Prandtl sayıları için gösterilmiştir. Şekil 3 (a), (b), (c) ve (d)'de L/D=1.5; Şekil 3 (e), (f), (g) ve (h)'da L/D=5; Şekil 3 (a), (b), (e) ve (f)'de Pr=0.7; Şekil 3 (c), (d), (g) ve (h)'da Pr=7; Şekil 3 (a), (c), (e) ve (g)'de Re=100; Şekil 3 (b), (d), (f) ve (h)'da Re=200'dür. L/D'nin 1.5 olduğu durumlarda silindirler arasında girdap (vorteks) meydana gelmemekte iken, silindir arası uzaklık 5D olduğu durumda silindirler arasında girdap oluştuğu görülmektedir. $\mathrm{L} / \mathrm{D}=1.5$ durumunda birinci silindirden (öndeki silindirden) ayrılan hidrodinamik sinır tabaka, ikinci silindire temas etmemekte ve iki silindir sanki tek silindir gibi davranış sergilemektedir. L/D'nin 5 olduğu durumda ise birinci silindirden ayrılan hidrodinamik sınır tabaka silindirler arasındaki vorteks oluşturmak üzere kıvrılmakta ve ikinci silindire temas etmektedir. Her iki L/D konumunda ise aşağı akış bölgesinde de vorteks meydana geldiği görülmektedir. Özellikle Şekil 3 (a)'nın (b)'ye, Şekil 3 (c)'nin (d)'ye, Şekil 3 (e)'nin (f)'ye, Şekil 3 (g)'nin (h)'a göre karşılaştırılmasında Reynolds sayısının yükselmesiyle birlikte vorteksler ikinci silindire daha yakın bir mesafede oluştuğu görülmektedir. Eş sıcaklık eğrileri incelendiğinde de, termal sınır tabakanın silindir ön yüzeyinde oluştuğu ve arkaya doğru genişlediği görülmektedir. Silindir arka duvarlarında sıcaklık gradyanları daha küçüktür. $\mathrm{L} / \mathrm{D}=5$ 'de eş sıcaklık eğrileri $\mathrm{L} / \mathrm{D}=1.5$ durumuna göre daha geniş yer kaplamaktadır. Ayrıca Prandtl sayısının artması ile aşağı akış bölgesinde yani silindir arkasında oluşan girdapların daraldığı görülmektedir. Bu durum Pr sayısının 0.7 değerinde 1sıl sınır tabakanın daha hızlı gelişmesinden kaynaklı olup, Pr=0.7'deki eş sıcaklık eğrileri, Pr=7'deki eş sıcaklık eğrilerine göre daha geniş alana yayılmaktadır.

Şekil 4'de silindirler için akışkanın hava (Şekil 4a) veya su (Şekil 4b) olması durumunda L/D=1.5 ve 5 değerlerinde ortalama Nusselt sayısının Re sayısı ile değişimi verilmiştir. Her iki akışkan ve L/D değerlerinde öndeki silindirde $\mathrm{Nu}$ sayısı arkadaki silindire göre daha yüksek çıkmıştır. Çünkü ilk silindir ile akışkan arasındaki sıcaklık farkı daha fazladır. Birinci silindirden ısınan akışkan ikinci silindire doğru yöneldiğinde sıcaklığı artmış. Böylelikle ikinci silindir ile akışkan arasındaki sıcaklık farkı azaldığından hesaplanan ortalama Nusselt sayısı daha az çıkmıştır. Re sayısının artmasıyla Nu değeri de artmışıı. Şekil 4a'da her iki silindir için de tüm Re değerlerinde $\mathrm{Nu}$ sayısı $\mathrm{L} / \mathrm{D}=5$ durumunda $\mathrm{L} / \mathrm{D}=1.5$ durumuna göre daha büyüktür. Bunun nedeni; Şekil 3'teki eş sıcaklık ve girdap eğrilerinden de görüleceği gibi $\mathrm{L} / \mathrm{D}=1.5$ durumunda silindirler arasında akışkanın durgun olmasıdır. L/D değerinin artmasıyla $\mathrm{Nu}$ değerinin artması her iki silindirde de gözlenirken bu artış arkadaki silindirde çok daha fazla olmuştur. Bu değişimler akışkanın su (Şekil 4b) olması durumunda da geçerlidir. L/D değerinin arttırılması Nu sayısını artııırken akışkanın su olması durumunda bu artış daha fazla olmuştur. Tüm Re ve L/D değerlerinde akışkanın su olması durumunda yani yüksek Pr sayısında Nu değerleri daha yüksektir. $\mathrm{Re}=150, \mathrm{~L} / \mathrm{D}=5$ değerinde öndeki silindir için akışkan hava iken Nu değeri 6.5 civarındayken akışkan su olduğunda yaklaşık 16 değerindedir.

İki farklı L/D değerinde akışkanın hava ( $\mathrm{Pr}=0.7)$ olduğu durumda Strouhal sayısının hem birinci hemde ikinci silindir için Reynolds sayısı ile değişimi Şekil 5'te verilmiştir. Her iki L/D değerinde de Reynolds sayısının artmasıyla Strouhal sayısı artmıştı. Sabit Reynolds sayısında $\mathrm{L} / \mathrm{D}=5$ değerinde $\mathrm{St}$ sayısı $\mathrm{L} / \mathrm{D}=1.5$ değerindekinden daha büyüktür. $\mathrm{Bu} \mathrm{L} / \mathrm{D}=5$ durumunda silindirler arasında oluşan vortekslerin periyodunun $\mathrm{L} / \mathrm{D}=1.5$ durumunda oluşan vortekslerin periyodundan daha büyük olduğunu göstermektedir. Düşük $\mathrm{Re}$ sayısında L/D değerleri için St sayısındaki fark fazlayken Re sayısının artmasıyla bu fark azalmıştır. 


\begin{tabular}{|c|c|c|}
\hline & $\begin{array}{l}\text { BŞEÜ Fen Bilimleri Dergisi } \\
7(1), 342-353,2020\end{array}$ & $\begin{array}{r}\text { BSEU Journal of Science } \\
\text { DOI: } 10.35193 / \text { bseufbd.711597 }\end{array}$ \\
\hline U & & $8-7575$ (http://dergipark.gov.tr/bseufbd) \\
\hline
\end{tabular}

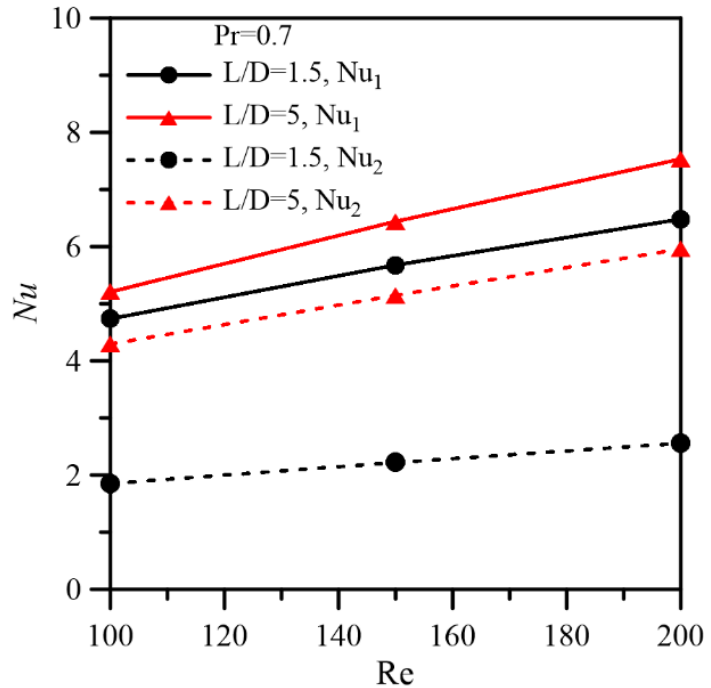

(a)

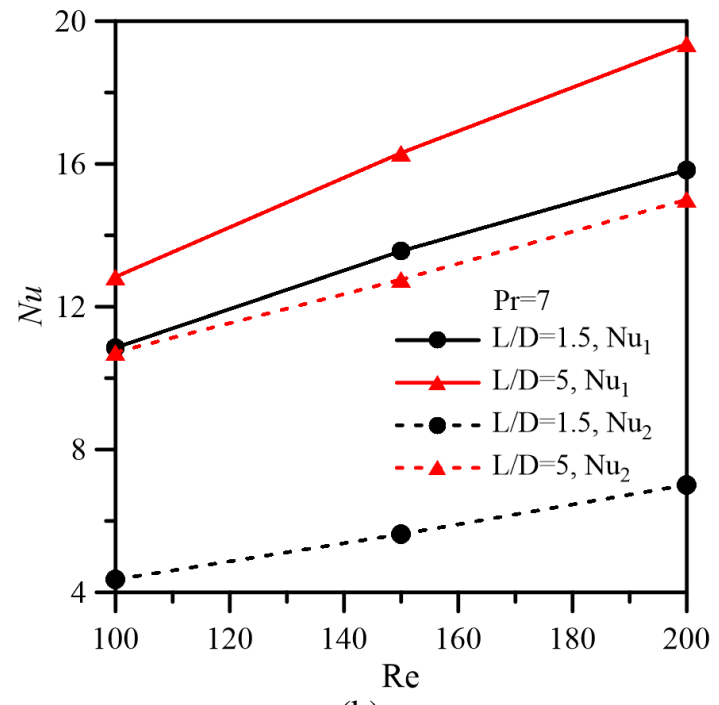

(b)

Şekil 4. (a) $\operatorname{Pr}=0.7$ ve (b) $\operatorname{Pr}=7$ için silindirler üzerindeki ortalama Nusselt sayılarının silindirler arasındaki uzaklık ve Reynolds sayısı ile değişimi (1 ve 2 indisleri sırasıyla 1 . ve 2 . silindir üzerindeki değerlerdir.)

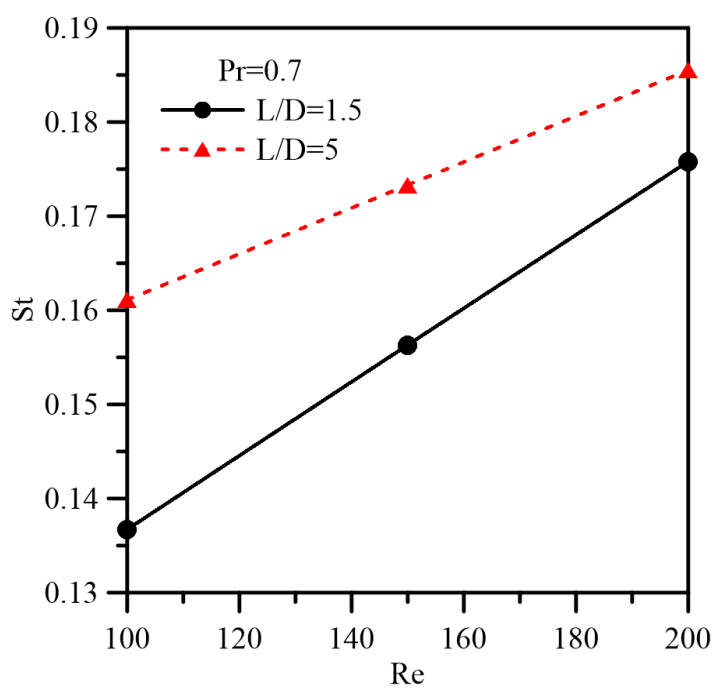

Şekil 5. Strouhal sayısının Reynolds sayısı ve iki silindir arası uzaklık değişimi ile ilişkisi

Şekil 6' da akışkanın hava olması durumunda 2 farklı silindir arası mesafe için (L/D=1.5 ve 5) ortalama sürüklenme katsayısının Re ile değişimi verilmiştir. Silindirler arası mesafe arttıkça, ortalama sürüklenme katsayıları değerleri de artmışıı. Re sayısının artması $\mathrm{L} / \mathrm{D}=1.5$ durumunda ortalama sürüklenme katsayısını düşürürken, $L / D=5$ durumunda $R e=150$ değerinden sonra çok az yükselir. Örneğin; Reynolds sayısı 150'deki ortalama sürüklenme değeri Reynolds sayısı 200'e göre L/D oranı 1.5 için mutlak farkı yaklaşık \%4 azalırken, L/D oranı 5 için \% 1'lik bir artış göstermiştir. 


\begin{tabular}{|c|c|c|}
\hline & $\begin{array}{l}\text { BŞEÜ Fen Bilimleri Dergisi } \\
7(1), 342-353,2020\end{array}$ & $\begin{array}{r}\text { BSEU Journal of Science } \\
\text { DOI: } 10.35193 / \text { bseufbd.711597 }\end{array}$ \\
\hline U & & $8-7575$ (http://dergipark.gov.tr/bseufbd) \\
\hline
\end{tabular}

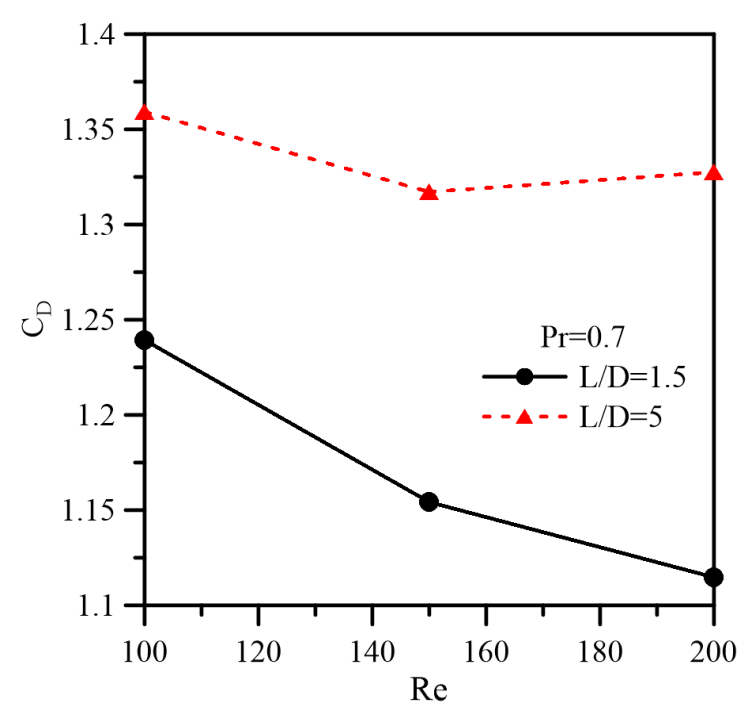

Şekil 6. Pr=0.7 için Reynolds sayısı ve iki silindir arası uzaklık değişiminin ortalama sürüklenme katsayısı üzerine etkisi

Tablo 2. 1. ve 2. silindir için ortalama $\mathrm{C}_{\mathrm{L}}$ değerleri

\begin{tabular}{ccccccccc}
\hline & \multicolumn{3}{c}{$\mathbf{C}_{\mathbf{L}, \mathbf{1}}$} & & \multicolumn{3}{c}{$\mathbf{C}_{\mathbf{L}, \mathbf{2}}$} \\
\cline { 2 - 9 } $\mathbf{R e}$ & $\mathbf{P r}=\mathbf{0 . 7}$ & $\mathbf{P r}=\mathbf{7}$ & $\mathbf{P r}=\mathbf{0 . 7}$ & $\mathbf{P r}=\mathbf{7}$ & $\mathbf{P r}=\mathbf{0 . 7}$ & $\mathbf{P r}=\mathbf{7}$ & $\mathbf{P r}=\mathbf{0 . 7}$ & $\mathbf{P r}=\mathbf{7}$ \\
\cline { 2 - 10 } & $\mathbf{L} / \mathbf{D = 1 . 5}$ & $\mathbf{L} / \mathbf{D = 5}$ & $\mathbf{L} / \mathbf{D = 1 . 5}$ & $\mathbf{L} / \mathbf{D = 5}$ & $\mathbf{L} / \mathbf{D}=\mathbf{1 . 5}$ & $\mathbf{L} / \mathbf{D = 5}$ & $\mathbf{L} / \mathbf{D = 1 . 5}$ & $\mathbf{L} / \mathbf{D = 5}$ \\
\hline 100 & \pm 0.0182 & \pm 0.4211 & \pm 0.0182 & \pm 0.4211 & \pm 0.0509 & \pm 1.6093 & \pm 0.0509 & \pm 1.6093 \\
150 & \pm 0.0195 & \pm 0.5768 & 0.0195 & \pm 0.5768 & \pm 0.0511 & \pm 1.5136 & \pm 0.0511 & \pm 1.5134 \\
200 & \pm 0.0211 & \pm 0.7153 & 0.0211 & \pm 0.7153 & \pm 0.0539 & \pm 1.5480 & \pm 0.0539 & \pm 1.5482 \\
\hline
\end{tabular}

Akışkanın hava ve su olması durumunda farklı Re sayılarında ve silindirler arası farklı mesafelerin olması durumunda her iki silindir için de elde edilen ortalama kaldırma kuvveti katsayısı Tablo 2'de verilmiştir. Ortalama kaldırma katsayısı, Reynolds sayısına bağlı olarak bir veya her iki silindirden girdap dökülmesine bağlı olarak periyodik olarak salınmaktadır. Bununla birlikte, salınımın genliği Reynolds sayısına ve L/D oranına bağlıdır. $\mathrm{L} / \mathrm{D}=1.5$ durumunda yani silindir eksenleri arası mesafe az iken $\mathrm{C}_{\mathrm{L}}$ değerleri her iki silindir için de düşük iken $\mathrm{L} / \mathrm{D}=5$ durumunda $\mathrm{C}_{\mathrm{L}}$ değerinde artış olmuştur. Bunun nedeni mesafe arttıkça arada vorteksler oluşmaya başlamıştır. Re sayısının değişimi CL değerlerinde ilk sıradaki silindirde daha etkili olurken arkadaki silindirde tüm durumlar için çok büyük değişiklik yaratmamıştır.

\section{SONUÇLAR}

Bu çalışmada iki silindir arası ve arkasındaki akış ve 1sı geçişinin etkisi $R e=100,150$ ve 200; L/D=1.5 ve 5 için sayısal olarak analiz edilmiştir. Çalışmadan elde edilen sonuçlar aşağıdaki gibi özetlenebilir.

- Akış alanındaki girdap eğrileri ile eş sıcaklık eğrilerinin benzer olduğu gözlenmiştir.

- Akış alanındaki girdap eğrileri incelendiğinde $\mathrm{L} / \mathrm{D}=1.5$ olduğunda silindirler arasında girdapların oluşmadığı ve akış alanı tek bir silindir haline benzediği görülmüştür. İki silindir arası 5D olduğunda ise silindirler arasında da girdaplar oluşmuştur.

- L/D değerinin arttırılması Nu sayısını arttırırken akışkanın su olması durumunda bu artış daha fazla olmuştur.

- Silindirler arası mesafe arttıkça, ortalama sürüklenme katsayıları değerleri de artmıştır. Ayrıca ortalama kaldırma katsayısı, Reynolds sayısına bağlı olarak bir veya her iki silindirden girdap dökülmesine bağlı 
olarak periyodik olarak salınım göstermektedir ve bu salınımın genliği Reynolds sayısına ve L/D oranına bağlıdır. Örneğin, düşük Reynolds sayısı ve L/D oranı için, genlik çok küçüktür.

- Silindirler arasında girdap oluşumu için kritik uzaklığın belirlenebilmesi için L/D oranı daha fazla çeşitlendilerek, silindirler arası vortekslerin meydana geldiği kiritik uzaklık belirlenerek çalışma zenginleştirilebilir.

\section{KAYNAKLAR}

[1] Farrant, T., Tan, M. \& Price, W.G., (2000). A cell boundary element method applied to laminar vortex shedding from circular cylinders. Journal of Fluids and Structures, 14(3), 375-402.

[2] Meneghini, J.R., Saltara, F., Siqueira, C.L.R. \& Ferrari, J.A., (2001). Numerical simulation of flow interference between two circular cylinders in tandem and side-by-side arrangements. Journal of Fluids and Structures, 15, 327-350.

[3] Buyruk, E., (2002). Numerical study of heat transfer characteristics on tandem cylinders, inline and staggered tube bank in cross-flow of air. International Communications in Heat and Mass Transfer, 29(3), $355-366$.

[4] Kondo, N. \& Matsukuma, D., (2005). Numerical simulation for flow around two circular cylinders in tandem. International Journal of Computational Fluid Dynamics, 19 (4), 277-288.

[5] Carmo, B.S. \& Meneghini, J.R., (2006). Numerical investigation of the flow around two circular cylinders in tandem. Journal of Fluids and Structures, 22(6-7), 979-988.

[6] Huang, Z., Olson, J.A., Kerekes, R.J. \& Green, S.I., (2006). Numerical simulation of the flow around rows of cylinders. Computers \& Fluids, 35(5), 485-491.

[7] Ding, H., Shu, C., Yeo, Y.O. \& Xu, D., (2007). Numerical simulation of flows around two circular cylinders by mesh-free least square-based finite difference methods. International Journal for Numerical Methods in Fluids, 53(2), 305-332.

[8] Mahir, N., Altaç, Z., (2008). Numerical investigation of convective heat transfer in unsteady flow past two cylinders in tandem arrangements. International Journal of Heat and Fluid Flow, 29, 1309-1318.

[9] Chatterjee, D., \& Mondal, B., (2012). Forced convection heat transfer from tandem square cylinders for various spacing ratios. Numerical Heat Transfer Part A: Applications, 61(5), 381-400.

[10] Abbasi, W.S., Shams-Ul-Islam, Saha, S.C. et al. (2014). Effect of Reynolds numbers on flow past four square cylinders in an in-line square configuration for different gap spacings. Journal of Mechanical Science and Technology, 28, 539-552.

[11] Ul Islam, S., Rahman, H. \& Zhou, C.Y., (2016). Effect of gap spacings on flow past row of rectangular cylinders with aspect ratio 1.5. Ocean Engineering, 119, 1-15.

[12] Zhang, W., Yang, H., Dou H.S. \& Zhu, Z., (2017). Forced convection of flow past two tandem rectangular cylinders in a channel. Numerical Heat Transfer, Part A: Applications, 72(1), 89-106.

[13] Shaaban, M. \& Mohany A., (2018). Flow-induced vibration of three unevenly spaced in-line cylinders in cross-flow. Journal of Fluids and Structures, 76, 367-383.

[14] Zhang, J., Chen, H., Zhou, B. \& Wang, X., (2019). Flow around an array of four equispaced square cylinders. Applied Ocean Research, 89, 237-250.

[15] Jue, T.C., Wu, H.W. \& Huang, S.Y., (2001). Heat transfer predictions around three heated cylinders between two parallel plates. Numerical Heat Transfer, Part A: Applications, 40(7), 715-733. 
[16] Rahnama, M. \& Hadi-Moghaddam, H., (2005). Numerical investigation of convective heat transfer in unsteady laminar flow over a square cylinder in a channel. Heat Transfer Engineering, 26(10), 21-29.

[17] Chatterjee, D., and Mondal, B., (2013). Mixed convection heat transfer from tandem square cylinders for various gap to size ratios. Numerical Heat Transfer, Part A: Applications, 63(2), 101-119.

[18] Barros, G.M., Lorenzini, G., Isoldi, L.A., Rocha, L.A.O. \& dos Santos, E.D., (2017). Influence of mixed convection laminar flows on the geometrical evaluation of a triangular arrangement of circular cylinders. International Journal of Heat and Mass Transfer, 114, 1188-1200.

[19] Sunakraneni, S., Puliyeri, V. \& Prakash, AK., (2018). Fluid flow and heat transfer characteristics past two tandem elliptic cylinders: a numerical study. Journal of Enhanced Heat Transfer, 25(4-5), 421-441.

[20] Slaouti, A., Stansby, P.K., (1992). Flow around two circular cylinders by the random vortex method. Journal of Fluids and Structures, 6, 641-670. 